\title{
INTELLIGENT ENERGY MANAGEMENT CONTROLLER USED IN INDUSTRIAL APPLICATIONS
}

\author{
Rohit Wanjari $^{1}$, Ankit Wade ${ }^{2}$, Snheha Satpute ${ }^{3}$, Diksha Lanjewar ${ }^{4}$, S.A. Kale ${ }^{5}$ \\ ${ }^{1}$ Electrical Department, RTMNU, Nagpur \\ ${ }^{2}$ Electrical Department, RTMNU, Nagpur \\ ${ }^{3}$ Electrical Department, RTMNU, Nagpur \\ ${ }^{4}$ Electrical Department, RTMNU, Nagpur \\ ${ }^{5}$ Project Guide, Department of Electrical Engineering
}

\begin{abstract}
The basic idea Behind INTELLIGENT ENERGY MANAGEMENT CONTROLLER USED IN INDUSTRIAL APPLICATIONS is to manage the power in various loads. These loads are models for the different units in industry. Hence to avoid this we design a hardware. When any load increases then other connected load is disconnected. The sequence of disconnecting the loads is based on the priority that is provided by the Micro controller. The priority of the loads can be changed as per requirement.
\end{abstract}

$* * *$

\section{INTRODUCTION}

In industries we have seen various types of arrangement used for proper functioning of various units in respective industries. As we seen large amount of power is wastage because there is a lack of planning and monitoring of power distribution to various units. Due to this industrial and other organization are going to faces major problems such as power and production losses, material wastage, industrial breakdown and much more.

IEMC includes planning and operation of energy .Aim is to provide protection to the equipment in industries. In short Power management is proper distribution of power in different loads.

In this project we are going to conserve energy by deciding priority of loads according to requirement of production. In this project we are doing step wise management by using Micro controller known as INTELLIGENT ENERGY MANAGEMENT CONTROLLER . with the help of these concept we can provide sufficient power to the various loads in system according to their requirements. These loads are models for the different units in industry. If the load in any area increases then there may be chances of tripping plant. Hence to avoid this we design a hardware.

\section{Power Management}

The sequence of disconnecting the loads is based on the decided priority that is provided through Micro controller The sequence of disconnecting the loads can be changed. With the help of micro controller we giving the priorities, a hardware $\mathrm{c}$ for disconnecting the load with the help of relay logic.

\section{SYSTEM BLOCK DIAGRAM}

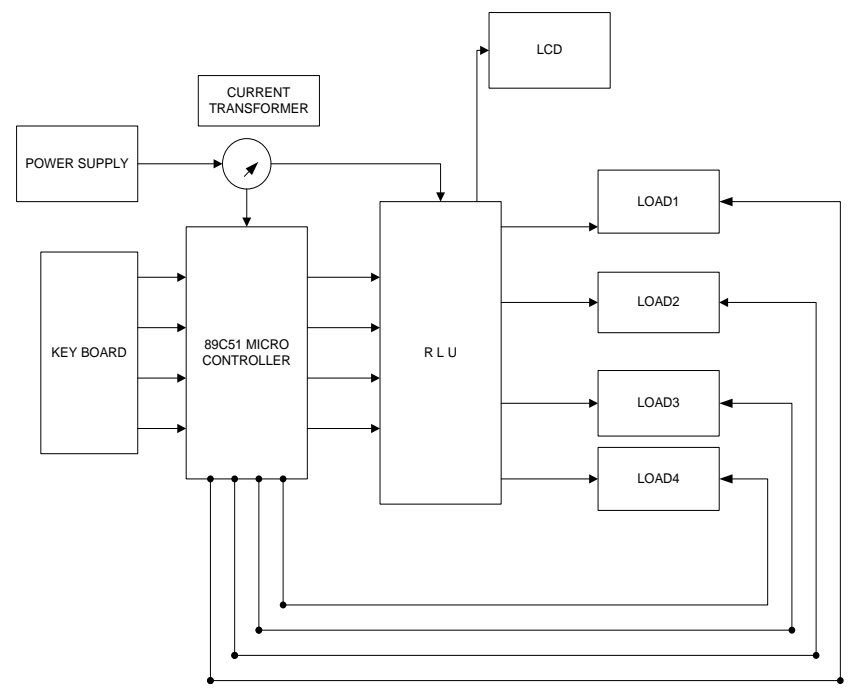

\subsection{Working}

The $\mathrm{o} / \mathrm{p}$ of C.T is given to IEMC. The total load current measured by the main current transformer. The line is connected to relay logic $\mathrm{n} / \mathrm{w}$. The $\mathrm{o} / \mathrm{p}$ of relay $\mathrm{n} / \mathrm{w}$ is connected to different load. The load currents are measured by different C.T. connected to the loads . o/p of those C.T is given to IEMC. The IEMC compare the reference voltage with variable voltage and give signal to relay. If the reference voltage is equal to the variable voltage then the load which is connected through relay is disconnected. The relay will connect or disconnect the loads according to given priority to relay. The sequence of getting of IEMC is fixed but due to the relay logic the loads are disconnected according to priority. 


\subsection{Major Components Used}

- CURRENT TRANSFORMER-It is used to measurement of alternating electric current.

- RELAY LOGIC. UNIT- To connect the load to the input side that is the power generation side

- 89C51 MICRO CONTROLLER- advantage that it can be erased and program to a maximum of 1000 times.

- ENERGY METER- Energy meter is a device that measure the amount of electric energy.

- LOAD- According to applications we used loads which are industrial loads, commercial loads ,Municipal loads

\subsection{Relay}

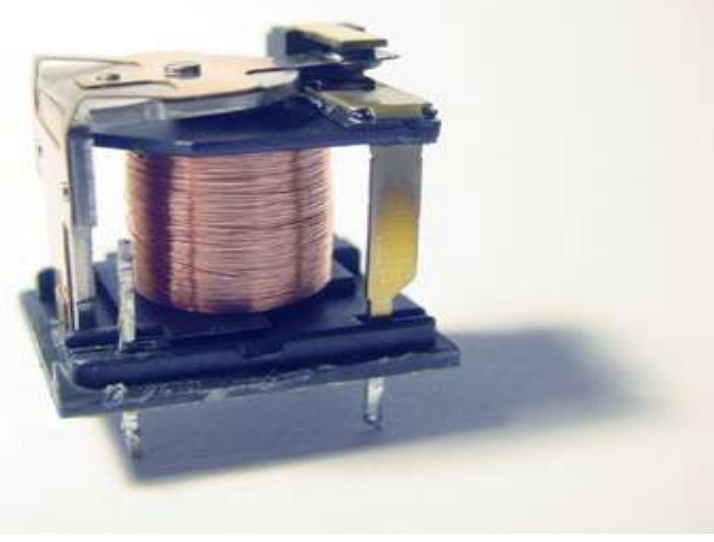

The benefit of relays is that it can operate automatically when fault occurs in that circuit and it can operated manually in normal condition to on and off the circuit

\section{CIRCUIT DIAGRAM:}

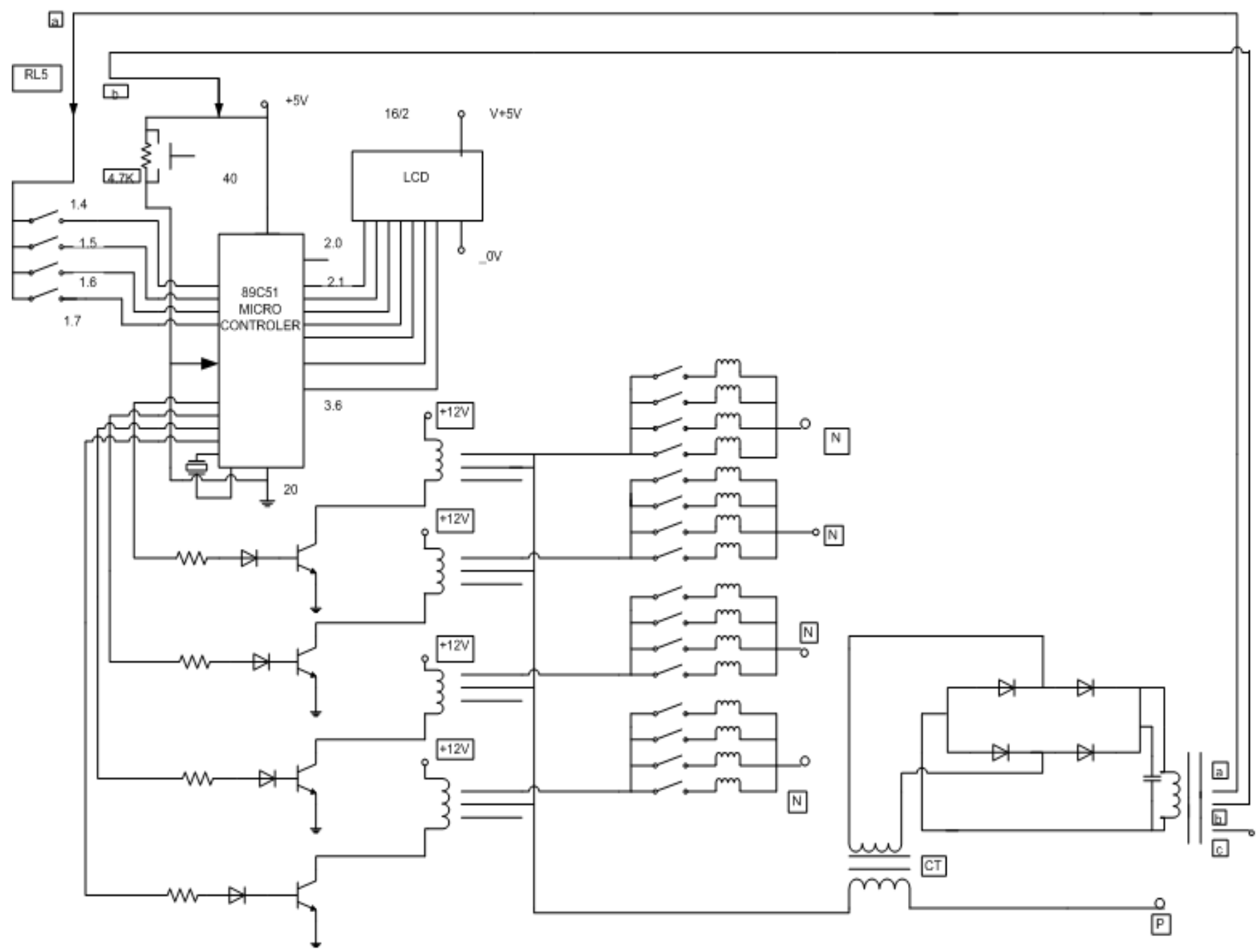




\section{SWITCHING PATTERN}

\begin{tabular}{|c|c|c|c|c|}
\hline SWITCH & $\begin{array}{l}\text { CLOTH } \\
\text { INDUSTRY }\end{array}$ & $\begin{array}{l}\text { SNACK } \\
\text { INDUSTRY }\end{array}$ & $\begin{array}{l}\text { FOOD } \\
\text { INDUSTRY }\end{array}$ & $\begin{array}{l}\text { MEDICINE } \\
\text { INDUSTRY }\end{array}$ \\
\hline 1 & $3(75 \%)$ & $1(25 \%)$ & $2(50 \%)$ & $4(100 \%)$ \\
\hline 2 & $1(25 \%)$ & $2(50 \%)$ & $4(100 \%)$ & $3(75 \%)$ \\
\hline 3 & $4(100 \%)$ & $2(50 \%)$ & $1(25 \%)$ & $3(75 \%)$ \\
\hline 4 & $2(50 \%)$ & $1(25 \%)$ & $3(75 \%)$ & $4(100 \%)$ \\
\hline
\end{tabular}

Fig.1 Power Distribution

Consider industrial area which includes four different industries such as medicine, food, clothes and snacks industry. The power consumption of each industry is different from each other as shown in above table. In our project we are deciding the priority of the load according to their power consumption which varies day by day. According to our concept when the overall system is overloaded then the load is automatically disconnected from the main supply which having least priority. In short we provide continuous supply to those industries which having maximum power.

In this way we did power management by which we save the power and provide protection to the equipment which is used in industries.

\section{CONCLUSION}

In this way we did distribution of power via different loads by deciding priority with the help of micro controller. The challenge to the experiment is that operator should have proper knowledge of power management. When system is overload load which having least priority is automatically disconnected. Some communication is required between the industries and control panel by which control panel decide their priority. Here proper communication is required between control panel and industries.

\section{REFERENCES}

[1] C Abbey and G Joos. Energy management strategies . In PESC record IEEE annual power electronics specialists conference, 2005.

[2] S Abras, S Ploix, S Pesty, and M Jacomino. A multiagent design for a home automation system .A AlAlawi, S M Al-Alawi, and M Islam Syed. Renewable energy, 8(32), 2007.

[3] J Kwi-Seong, L Wong-Yong, and K Chang-Soo. Energy management strategies and technical challenges. IEEE Transactions on Power Systems, 22(4), 2007.

[4] S.D.J McArthur, E.M. F. Ponci, and T. Funabashi. Morgan Kaufmann, (pp. 357-366). 1988.

[5] 15. Handbook on Energy Audits and Management M. G. Simoes, F. A. Farret, Renewable Energy Sources, CRC press, 2004.

[6] A Textbook of Electrical Technology -B.L. THEREJA And A.K.THEREJA .

[7] The 8051 Microcontroller and Embedded SystemMohammad Ali Mazidi.

[8] Electric Machines - Ashfaq Husain. 